\section{Lightening a donkey's burden}

A European Commission plan to use donkeys assisted by helium balloons, which would allow them to carry greater weights of biowaste down the mountains of the Abruzzo region near Rome waste that would be converted to 'bunker oil' in small pyrolytic converters - has caused palpitations among some careful biotechnologists in the Commission, who fear it has threatened their modest but important attempt to move European chemical industries towards the use of agricultural feedstocks rather than coal or oil.

The Commission's "Concertation Unit for Biotechnology" (CUBE) has long argued the economic case against biofuels, and for some years has been energetically but soberly pursuing the development of biotechnology and its applications in Europe. But two weeks ago, CUBE members had heard nothing of the Abruzzo proposals, which had emerged largely through reports in the British press.

CUBE officials were privately furious that the Commission had been effectively (though unintentionally) smeared by connection with some of the more exaggerated aspects of the Abruzzo scheme, which began as the project of a small Italian entrepreneurial company, Italenergie, and has already been promised a pilot 46,000 million lira ( $£ 23$ million) from the Italian regional authorities. The project's proponents in the Commission, who appear to have been taken in by an energy consultant's tongue-in-cheek remark that the transport of the 320,000 tonnes of waste a year envisaged in the full $£ 150$ million, 5-7-year scheme would be aided if the local donkeys were attached to balloons, are more sanguine about the proposal than are the CUBE people. Balloons aside, they aim to raise 33,000 million lira from the Commission's agricultural, development and social funds in support of the scheme, which would therefore not touch the Commission's research budget. These funds would buy 11 modular pyrolytic units each to convert one tonne of biowaste per hour to a kind of fuel oil with about half the calorific value per unit volume of ordinary oil.

Working with material from woods, wastelands and hilly regions, some 6 per cent of the energy requirements of the Abruzzo region could be met with the 30 40 pyrolytic converters of the scheme, together with a 27-megawatt electric power station (with district heating using waste heat) fired by the biofuel at a cost of around $\$ 22$ a barrel - admittedly dear at today's oil prices.

If the scheme - or the donkeys - get off the ground, biowaste may be extended by the addition of energy crops for margi- nal land, such as yellow broom. This needs no fertilizer or irrigation, is insensitive to soil $p \mathrm{H}$, and can be cropped at 10 tonnes per hectare per year, say supporters. In the longer term sweet sorghum on good soils could yield 14 tonnes of bioethanol per hectare per year, compared with the

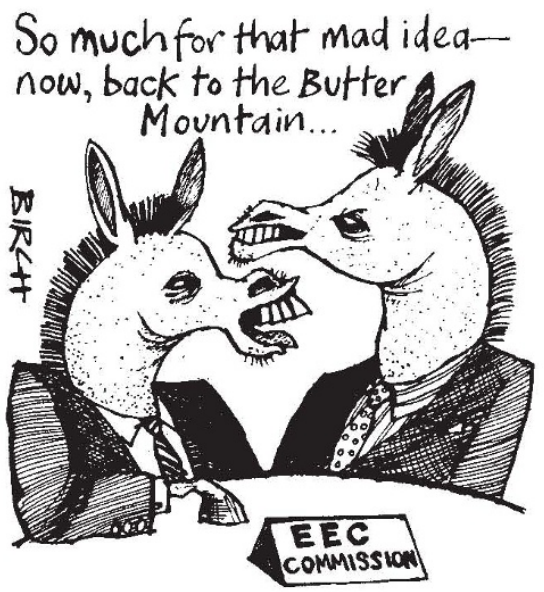

2.5-5 tonnes at present available from sugar beet. CUBE, the European Parliament and others have rejected bioethanol, a potential additive for transport fuel, as

\section{Milan}

A NEw government bill is to be placed before the Italian parliament within the next year establishing a Ministry of Research and Technology. The bill will appear in the wake of legislation now making its way through the Italian legislature reorganizing CNR, the Italian National Research Council.

The reorganization has taken nearly 25 years to evolve, a product of much discussion between political parties, unions and research institutes, and represents a new commitment to research and development in Italy.

Italy has been slowly increasing the resources devoted to research in its attempt to reach a goal of 2.5 per cent of gross national product (GNP). The research budget from government coffers is still about 1 per cent short of that goal, although it has increased by 20.8 per cent (14 per cent in real terms) since 1985 . The private sector and the public companies will share half of a budget which now totals 11,000 million million lire.

The new legislation represents a commitment by the Italians to improve the facilities and resources available to science. There are already $\mathbf{1 1 2 , 8 8 4}$ full-time staff in the research institutes of whom about half are engaged directly in research, making the average cost per researcher in Italy

uneconomic at present production costs based on sugar beet.

With its feet firmly planted on the ground, however, CUBE has been promoting something quite different: research to close the gaps between the chemistry of certain agricultural products, such as starch, and the carbon chains and other inputs required by the chemical industries. "We want a modest start to something of real strategic significance", said a CUBE spokesman. He did not want to "knock" the Abruzzo project, "which probably has real local and regional significance" (among other things it would create 2,000 jobs). He added that it was unfortunate that the fanciful flying donkey had emerged just as the CUBE "agroindustrial" project was approaching critical funding decisions by European research ministers.

But, it emerged last week that the prospects of EEC backing for the CUBE proposals had diminished. A European research ministers' meeting classified the project as "controversial". But, according to officials in Britain currently presiding over the meeting, the donkeys had had no influence on the downgrading. Matters such as funding levels in tight budgets and demarcation disputes between ministries of agriculture and industry were more to blame.

Robert Walgate

\title{
Italy to have research ministry at last
}

about 130 million lire, roughly comparable to that in other developed countries.

According to Senator Luigi Granelli, the Italian Minister of Research, this is a very important time for the country's research and with more resources and reorganization, much more efficiency can be achieved. Based on the Science Citation Index, scientific productivity in Italy has improved substantially since 1983 , lifting it from twelfth to eighth place last year.

That improvement will continue as a result of three principal measures. First, a commitment of an additional 1,500 million million lire over a three-year period for national research programmes involving research institutions and private industry, second, better industrial research with 100 million million lire a year over ten years through credits to industry from the Istituto Mobiliare Italiano (IMI) for applied research; and a national programme for research in biotechnology to start next year costing $\mathbf{4 0 0}$ million million lire.

The national funds for CNR will also be increased in the next twelve months to about 900 million million lire. Furthermore, an additional $\mathbf{7 2 0}$ million million lire in five years will be added to a 300 million million lire fund from industry, earmarked to improve the quality of researchers through 635 educational and training programmes.
Paola De Paoli 